\title{
Geheimrat Prof. Dr. Wilhelm Schmidle zum Gedenken
}

Als Geheimrat WILHELM SCHMIDLE am I2. Februar 1952 - 92jährig in der Dorfkirche zu Günterstal bei Freiburg im Breisgau zu Grabe getragen wurde, schied ein Mann von uns, der nach zwei Richtungen hin mit der Hydrobiologie und Limnologie verbunden war: als Algologe, der um die Jahrhundertwende zu den besten Algenkennern Europas zählte und dessen Name als Autor in zahlreichen Diagnosen von Grün- und Blaualgen verewigt ist, sodann als Geologe, dem wir in hohem Masse unsere heutigen Kenntnisse über die Entstehung und geologische Geschichte des Bodenund des Untersees sowie ihrer näheren Umgebung verdanken. Seiner besonderen Verbundenheit mit der Schweiz verlieh er Ausdruck durch die Schenkung seiner wertvollen Algensammlung sowie des botanischen Teils seiner Bibliothek an das Institut für spezielle Botanik der Eidgenössischen Technischen Hochschule.

Erst auf Umwegen fand der an Mathematik und Physik besonders interessierte junge Schulmann, der in Baden-Baden seine erste Stelle als Lehramtspraktikant antrat, den Weg zur Botanik, insbesondere zur Algologie. Aber als er dank der Begegnung mit dem nachmaligen Karlsruher Botaniker KLEIN mit den mikroskopischen Arbeitsmethoden vertraut geworden war und von dem Freiburger Forstzoologen und hervorragenden Rheinforscher Prof. ROBERT LAUTERBorN bedeutsame Anregungen erhalten hatte, erwarb er sich in seinem wissenschaftlichen Wirkungsfelde bald einen so guten Namen, dass deutsche Kollegen und Fachleute aus aller Welt ihm die auf Expeditionen in fernen Ländern gesammelten Algenmaterialien zur Bestimmung und Erstbeschreibung überliessen.

Als aber WILHELM SCHMIDLE nach verschiedenen Versetzungen - nach Müllheim und kurz darauf nach Mannheim - als Direktor das grosse und sehr mühsame Internat des Lehrerseminars Meersburg übernehmen musste, war es um die geruhsame Arbeit am Mikroskop endgültig getan. In dem Zeitpunkt, da er sich stark genug fühlte, um zusammenfassende Werke über die Systematik verschiedener Algengruppen zu verfassen, musste er der Algologie Valet sagen.

Um dennoch seiner Wissenschaft zu leben, ohne die er sich unglücklich fühlte, zog er auf Exkursionen ins Land hinaus und arbeitete sich dabei so 
gründlich in die geologischen Fragen der Bodenseegegend hinein, dass er schliesslich zum Spezialisten und zur ersten Autorität auf diesem Gebiet wurde. Die Untersuchungen Pencks über die diluvio-geologischen Verhältnisse des Bodensees mögen dabei den Anstoss gegeben haben, und in der Freundschaft mit dem badischen Landesgeologen SCHALCH und dem Freiburger Geologen DEECKE fand er weitere Anregung und tatkräftige Förderung.

Nach fünfjähriger aufreibender Tätigkeit am Meersburger Seminar führte ihn der Weg für kurze Zeit nach Karlsruhe (1907), aber er war glücklich, als ihn die Stadt Konstanz wieder an seinen geliebten Bodensee zurückrief und zum Direktor ihrer Oberrealschule ernannte. In diese Zeit (1908-1924) fallen seine meisten geologischen Publikationen. Morphologie und Diluvialgeologie, Molassestratigraphie, Tektonik und Hegauvulkanismus standen dabei im Vordergrund. Die Anerkennung für diese reiche wissenschaftliche Tätigkeit fand ihren Ausdruck in der Verleihung des Doktortitels ehrenhalber durch die Freiburger Universität.

Mit 64 Jahren verliess Geheimrat SCHMIDLE den Staatsdienst, um (I924) die Leitung der Salemer Schloßschulen zu übernehmen, bis er sich nach zurückgelegtem siebzigstem Altersjahr in die Stille des Schwarzwalddorfes Günterstal zurückzog, um dort noch weitere 20 Jahre lang ungestört seine geologischen Studien fortzusetzen, treu umsorgt von seiner geliebten Gattin und, nach deren Hinschied, von seiner getreuen Pflegetochter MARIE WAI,DVOGEL.

Der hohen Anerkennung und dem verdienten Dank, den man bis zu seinem Tode dem früheren Salemer Lehrer entgegenbrachte, gab S. K. H. der Markgraf BERTHOLD von Baden in einer tiefempfundenen Grabrede schönen Ausdruck.

Wilhelm Schmide, ein Mann von lauterster Gesinnung und vorbildlicher Pflichterfüllung, repräsentierte den Typus des zuverlässigen, getreuen, zähen, temperamentvollen und immer frohen Schulmannes und Wissenschafters süddeutscher Prägung. In seiner Nähe fühlte man sich wohl, und einem jeden jungen Wissenschafter erwuchs aus seiner Freundschaft reiche Anregung und Aufmunterung.

Otto Faag

Eine Zusammenstellung von WILHELM SCHMIDLES botanischen und gcologischen Publikationen (bis 194I) findet sich in: Mitteilungen fuir Naturkunde und Naturschutz, Organ des Badischen Landesvercins für Naturkunde und Naturschutz e. V., Freiburg im Breisgau: Neue Folge, Bd. 4, Heft 7, März I94I. 